\title{
CARACTERIZAÇÃO DOS FRUTOS E GERMINAÇÃO DE SEMENTES DOS PORTA-ENXERTOS TRIFOLIATA FLYING DRAGON E CITRUMELO SWINGLE ${ }^{1}$
}

\author{
FILIPE ALMENDAGNA RODRIGUES ${ }^{2}$, GUSTAVO DE FARIA FREITAS 3 , \\ RODRIGO AMATO MOREIRA ${ }^{4}$, MOACIR PASQUAL ${ }^{5}$
}

RESUMO-Objetivou-se realizar a caracterização fitotécnica dos frutos e avaliar o efeito da remoção do tegumento da semente e do uso do $\mathrm{GA}_{3}$ e do bioestimulante (Stimulate ${ }^{\circledR}$ ) sobre a germinação de sementes dos porta-enxertos de citros Flying Dragon e citrumelo Swingle. A caracterização fitotécnica compreendeu a massa do fruto, o diâmetro transversal e longitudinal e a espessura da "casca" e a contagem de sementes viáveis e inviáveis por fruto. Realizou-se um experimento para cada porta-enxerto, em casa de vegetação sob nebulização intermitente, e as avaliações foram a cada 3 dias, após o início do processo germinativo, verificando-se porcentagem de germinação e índice de velocidade de germinação. A utilização do $\mathrm{GA}_{3}$ e a retirada do tegumento em sementes do porta-enxerto Flying Dragon aumentam a porcentagem de germinação e o índice de velocidade de germinação, e para o porta-enxerto citrumelo Swingle, a retirada do tegumento das sementes aumenta a porcentagem de germinação e o índice de velocidade de germinação.

Termos para indexação: Citricultura, Índice de Velocidade de Germinação, Produção de Mudas.

\section{CHARACTERIZATION OF FRUITS AND SEED GERMINATION OF ROOTSTOCK TRIFOLIATA FLYING DRAGON AND CITRUMELO SWINGLE}

\begin{abstract}
The objective was phytotechnical characterization of fruits, evaluating the effect of removing the husk of the seed, the influence of $\mathrm{GA}_{3}$ and growth promoter (Stimulate ${ }^{\circledR}$ ) on the germination of seeds of rootstock Flying Dragon and Citrumelo Swingle. The phytotechnical characterization included the weight of the fruit, transverse and longitudinal diameter, thickness of the "peel" and the counting of viable and unviable seeds per fruit. There was an experiment for each rootstock in greenhouse under intermittent mist and the evaluations were every 3 days after the beginning of the germination process, verifying percentage of germination and germination speed. The use of $\mathrm{GA}_{3}$ and the removal of seed husk of the rootstock Flying Dragon increase the germination percentage and germination speed, and for the rootstock Citrumelo Swingle the removal of the seed husk increased the germination percentage and the germination speed.

Index terms: Citrus industry, Germination Speed, Production of Seedlings.
\end{abstract}

\footnotetext{
'(Trabalho 206-09). Recebido em: 02-09-2009. Aceito para pubilcação em: 10-02-2010.

${ }^{2}$ Mestrando em Agronomia/Fitotecnia, Universidade Federal de Lavras, Departamento de Agricultura, Caixa Postal: 3037, CEP: 37200-000, Lavras-MG. E-mail: filipealmendagna@yahoo.com.br - (autor para correspondência)

${ }^{3}$ Doutorando em Agronomia/Fitotecnia, Universidade Federal de Lavras. E-mail: freitasgf@yahoo.com.br

${ }^{4}$ Mestrando em Agronomia/Fitotecnia, Universidade Federal de Lavras. E-mail: amatomoreira@yahoo.com.br

${ }^{5}$ Professor Titular Universidade Federal de Lavras, E-mail: mpasqual@ufla.br
} 


\section{INTRODUÇÃO}

A citricultura brasileira é uma atividade de importância mundial, sendo o Brasil o maior produtor de citros (18 milhões t.ano ${ }^{-1}$ em 940 mil ha) e o maior exportador mundial de suco concentrado de laranja, (1,2 milhão t) (AGRIANUAL, 2008).

Apesar desta importância, ainda existe a necessidade de se encontrarem alternativas para solucionar alguns problemas inerentes à citricultura, como, por exemplo, a utilização massiva de um único porta-enxerto, limoeiro Cravo, na qual está sustentada a citricultura brasileira.

Mais recentemente, uma nova doença, a Morte Súbita dos Citros, pode colocar em risco a citricultura nacional, e está associada à combinação de laranjeiras-doce, tangerineiras e outros sobre limoeiro Cravo, uma vez que combinações dessas variedades sobre porta-enxertos de tangerineiras Cleópatra (Citrus reshni Hort. ex Tan.) e Sunki (Citrus sunki Hort. ex Tanaka), Poncirus trifoliata (L.) Raf. e citrumelo Swingle [P. trifoliata (L.) Raf. $\mathrm{X}$ Citrus paradisi Macf.] são resistentes aos sintomas da doença (SOARES FILHO, 1999).

O citrumelo Swingle é um híbrido entre Citrus paradisi Macf. e P. trifoliata, que tem como limitação a sua incompatibilidade com algumas variedades comerciais, tais como laranjeira Pera e tangerineira Murcott (MATTOS JUNIOR et al., 2005). Apesar desta limitação, tem sido utilizado com sucesso em combinações com as variedades comerciais Hamlin, Baía, Valência, Natal e Ponkan (FUNDECITRUS, 2008).

O trifoliata Flying Dragon é uma variação genética do trifoliata ( $P$. trifoliata var. monstrosa), sendo bastante resistente à gomose (Phytophthora spp.), tolerante à morte súbita dos citros e ao declínio. Devido à característica ananicante induzida pelo 'Flying Dragon', o controle fitossanitário, o desbaste de frutos e a poda de limpeza são facilitados (FUNDECITRUS, 2008).

O principal aspecto na obtenção do portaenxerto numa produção comercial de mudas cítricas refere-se à quantidade e à porcentagem de sementes germinadas, isto porque os porta-enxertos cítricos são normalmente propagados via seminífera. A germinação de sementes de porta-enxertos cítricos ocorre lentamente, levando um período de sessenta dias ou mais, o que faz com que o tamanho das plantas seja bastante desuniforme, sendo tal fato indesejável. $\mathrm{O}$ ideal seria que essas sementes germinassem rapidamente, originando plantas uniformes. Esse problema pode ser minimizado com o emprego de ácido giberélico ou bioestimulante vegetal, que tem a finalidade de acelerar e uniformizar a germinação de sementes.

As giberelinas têm papel-chave na germinação de sementes, estando envolvidas na superação da dormência e no controle de hidrólise das reservas, pela indução da síntese de novo $\alpha$-amilase, enzima responsável pela hidrólise do amido (LEVITT, 1974). De acordo com Taiz e Zeiger (2004), o equilíbrio entre hormônios, promotores e inibidores exerce papel fundamental na promoção da germinação e no crescimento inicial de plântulas.

Os bioestimulantes promovem o equilíbrio hormonal das plantas, favorecendo a expressão do seu potencial genético, estimulando o desenvolvimento do sistema radicular e agindo na degradação de substâncias de reserva das sementes, na diferenciação, divisão e alongamento celulares (ONO et al., 1999).

O Stimulate ${ }^{\circledR}$ (Stoller Interprises Inc.) é um estimulante vegetal contendo reguladores vegetais e traços de sais minerais quelatizados. Seus reguladores vegetais constituintes são ácido indolbutírico (auxina) a 0,005\%, cinetina (citocinina) a $0,009 \%$ e ácido giberélico (giberelina) a $0,005 \%$. Esse produto químico incrementa o crescimento e o desenvolvimento vegetal, estimulando a divisão celular, a diferenciação e o alongamento das células, também aumenta a absorção e a utilização dos nutrientes e é especialmente eficiente quando aplicado com fertilizantes foliares, sendo também compatível com defensivos (CASTRO et al., 1998). $\mathrm{O}$ uso de reguladores vegetais tem sido preconizado na fruticultura por diversos autores, como forma de melhorar a germinação das sementes e, em consequência, promover o crescimento das plantas jovens (HORE; SEN, 1993).

Objetivou-se realizar a caracterização fitotécnica dos frutos, avaliar o efeito da remoção do tegumento da semente e o uso de reguladores de

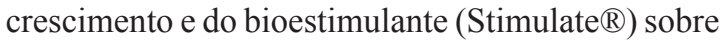
a germinação de sementes dos porta-enxertos de citros trifoliata Flying Dragon e citrumelo Swingle.

\section{MATERIAL E MÉTODOS}

O trabalho foi conduzido no Laboratório de Cultura de Tecidos Vegetais, no Departamento de Agricultura (DAG) da Universidade Federal de Lavras (UFLA), Lavras-MG, no período de março a julho de 2008.

Foram utilizados dois porta-enxertos de citros: o citrumelo Swingle [Citrus paradisi Macf. X Poncirus trifoliata (L.)] e o trifoliata Flying Dragon (P. trifoliata var. monstrosa). 


\section{Caracterização dos frutos}

Cinquenta (50) frutos maduros de cada porta-enxerto foram coletados no pomar do Setor de Fruticultura do DAG/UFLA e realizadas as seguintes avaliações: massa do fruto $(\mathrm{g})$ por meio de balança analítica, diâmetro transversal e longitudinal $(\mathrm{mm})$ e espessura da "casca" (epicarpo e mesocarpo) (mm), medidos com auxílio de um paquímetro e contagem de sementes viáveis e inviáveis por fruto.

Para a extração das sementes, realizaram-se corte superficial da casca no diâmetro transversal e torção do fruto, colocando as sementes em uma peneira. Após a lavagem, as sementes foram submetidas a teste de viabilidade que consistiu na colocação das sementes em um Becker com água. As sementes que boiaram, juntamente com as malformadas foram consideradas inviáveis. Após o teste, as sementes foram contadas e calculada a porcentagem de viabilidade das mesmas.

\section{Assepsia das sementes}

Todas as sementes foram tratadas com hipoclorito de sódio $(20 \%)$ por 3 minutos, posteriormente com álcool etílico $(70 \%)$ por 1 minuto e finalizando com tratamento térmico $\left(52^{\circ} \mathrm{C}\right)$ por 10 minutos.

\section{Germinação das sementes}

Foram realizados dois experimentos em casa de vegetação, sob nebulização intermitente, no período de abril a julho de 2008 , sendo um experimento para cada porta-enxerto.

Sementes dos porta-enxertos Flying Dragon e citrumelo Swingle foram semeadas em tubetes $\left(53 \mathrm{~cm}^{3}\right)$, contendo substrato comercial Plantmax ${ }^{\circledR}$ HT, uma semente por tubete e estes colocados em bandejas apropriadas sobre chão concretado.

$\mathrm{O}$ delineamento utilizado foi o inteiramente casualizado, em esquema fatorial $2 \times 3$, sendo os fatores: semente (com e sem tegumento) e imersão por 6 horas [em água destilada, $\mathrm{GA}_{3}\left(100 \mathrm{mg} \mathrm{L}^{-1}\right)$ e Stimulate $\left.{ }^{\circledR}\left(1,5 \mathrm{~mL} \mathrm{~L}^{-1}\right)\right]$. Foram utilizadas 4 repetições, sendo 10 sementes por parcela (1 semente por tubete).

A partir do início do processo germinativo, as avaliações foram realizadas a cada 3 dias, por um período de 60 dias Nessas avaliações, verificaramse a porcentagem de germinação e o índice de velocidade de germinação (IVG). As velocidades de germinação foram determinadas segundo o índice de velocidade de germinação (IVG), adaptado da fórmula de Maguire (1962), sendo:

em que:

$I V G=\left(G_{1} / N_{1}\right)+\left(G_{2} / N_{2}\right)+\ldots+\left(G_{n} / N_{n}\right)$,

$\mathrm{G}_{1}=$ número de sementes germinadas na primeira contagem;
$\mathrm{N}_{1}=$ número de dias decorridos até a primeira contagem;

$\mathrm{G}_{2}=$ número de sementes germinadas na segunda contagem;

$\mathrm{N}_{2}=$ númerodedias decorridosatéa segundacontagem,e $\mathrm{n}=$ última contagem.

Os dados obtidos foram submetidos à análise de variância, estudando a interação entre os fatores e a comparação das médias, pelo teste de Tukey, a 5\% de significância, com o uso do programa estatístico SISVAR (FERREIRA, 2000).

\section{RESULTADOS E DISCUSSÃO}

$\mathrm{Na}$ caracterização dos frutos, o citrumelo Swingle foi superior ao Flying Dragon nas variáveis analisadas (diâmetro transversal e longitudinal, massa do fruto, espessura da "casca" e sementes inviáveis), exceto para número de sementes viáveis (Tabela 1). O número total de sementes foi superior em frutos de citrumelo Swingle em relação ao Flying Dragon; entretanto, o número de sementes viáveis foi inferior (citrumelo Swingle 58\%) em relação ao porta-enxerto Flying Dragon (78\%).

Com relação à porcentagem de germinação (Figuras 1 e 2) e índice de velocidade de germinação (IVG) (Figuras 3 e 4), observou-se interação significativa entre os fatores semente e tratamento de imersão, apenas para o porta-enxerto Flying Dragon. Já para o citrumelo Swingle, não ocorreu interação significativa para as variáveis porcentagem de germinação e IVG, sendo observada diferença significativa somente para o fator tegumento. O processo de germinação das sementes é influenciado por uma série de fatores bióticos e abióticos, constituindo-se em uma fase crítica, sendo necessário um conjunto de condições favoráveis para que o mesmo possa ocorrer de forma satisfatória (BEWLEY; BLACK, 1994). A porcentagem de germinação é maior em sementes sem tegumento comparando-as com sementes que o apresentam, pois o tegumento funciona como uma barreira física que dificulta a absorção de água (OLIVEIRA; SCIVITTARO, 2007), deste modo retardando a ocorrência das reações químicas que desencadeiam o processo germinativo.

Em relação à porcentagem de germinação de sementes do Flying Dragon, a maior taxa $(18,33 \%)$ foi obtida quando se promoveu a retirada do tegumento das sementes, independentemente do produto utilizado na imersão (Figura 1A). Fortes (2002), e Oliveira e Scivittaro (2007) verificaram 
maior porcentagem de germinação quando retirado o tegumento das sementes do porta-enxerto trifoliata. Esse resultado indica que a prática da remoção do tegumento proporciona a redução do tempo para a formação de mudas.

Para o porta-enxerto citrumelo Swingle, foi obtida maior porcentagem de sementes germinadas (79,13\%) quando se promoveu a retirada do tegumento das sementes (Figura 1B). Resultados semelhantes foram observados por Zucareli et al. (2009) que, estudando a influência do tegumento na germinação de sementes de citrumelo Swingle, verificaram que a sua retirada favoreceu o processo germinativo.

A germinação de sementes de porta-enxertos cítricos ocorre lentamente, com isso o tamanho das plantas na sementeira é bastante desuniforme, o ideal seria se essas sementes apresentassem germinação mais homogênea (CHILEMBWE et al. 1992).

Analisando-se os tratamentos de imersão, verificou-se que o ácido giberélico $\mathrm{GA}_{3}(100 \mathrm{mg}$ $\left.\mathrm{L}^{-1}\right)$ favoreceu a germinação do Flying Dragon, em $22,5 \%$ (Figura 2), independentemente da retirada do tegumento das sementes. Resultados similares foram obtidos por Ynoue et al. (1999), com a utilização de $\mathrm{GA}_{3}$ em sementes de kiwi (Actinidia chinensis Planch.), observando um aumento na porcentagem de germinação.

O ácido giberélico age como promotor na germinação pela ação na liberação de enzimas hidrolíticas (KELLY, 1969). De acordo com Bernardes et al. (2008), a utilização de $\mathrm{GA}_{3}$ em sementes de pequi (Caryocar brasiliense Camb.) aumenta a porcentagem de germinação e reduz o tempo médio de emergência, contribuindo para a uniformização e desenvolvimento inicial das mudas, viabilizando a propagação comercial da espécie. Sousa et al. (2002) verificaram que o $\mathrm{GA}_{3}$ não influenciou na germinação de sementes dos porta-enxertos limoeiro Cravo, tangerineira Sunki, tangerineira Cleópatra, UFLAD-4 e UFLAD-5. No presente trabalho, o $\mathrm{GA}_{3}$ promoveu incremento na germinação das sementes dos dois porta-enxertos:
Flying Dragon e citrumelo Swingle. Metivier (1986) relata o papel-chave das giberelinas na germinação, estando envolvidas tanto na quebra da dormência como no controle da hidrólise de reservas, da qual depende o embrião em crescimento.

A germinação pode ter seu processo acelerado com o uso de reguladores de crescimento, como giberelinas. Pawshe et al. (1997) constataram este fato trabalhando com fruta-do-conde (Annona squamosa), onde obtiveram melhores taxas de germinação com $100 \mathrm{mg} \mathrm{L}^{-1} \mathrm{de} \mathrm{GA}_{3}$.

Para a variável índice de velocidade de germinação (IVG) do Flying Dragon, a imersão das sementes em $\mathrm{GA}_{3}$ apresentou valor superior aos demais tratamentos (Figura 3), ou seja, $I V G=0,22$, diferindo significativamente dos tratamentos com água $(\mathrm{IVG}=0,01)$ e Stimulate ${ }^{\circledR}(\mathrm{IVG}=0,06)$. Já para o IVG do citrumelo Swingle (Figura 4), a retirada do tegumento da semente proporcionou maior valor em relação à semente com tegumento.

O IVG é uma variável utilizada como indicador do vigor das sementes, ou seja, a sua habilidade em germinar em condições adversas (POPINIGIS, 1977). Stenzel et al. (2003), estudando a germinação de fruta-do-conde (A. squamosa), verificaram maior índice de velocidade de germinação das sementes tratadas com $\mathrm{GA}_{3}\left(50\right.$ e $\left.100 \mathrm{mg} \mathrm{L}^{-1}\right)$.

A evolução do processo germinativo das sementes do Flying Dragon durante um período de 60 dias é observada na Figura 5A, verificando-se baixa taxa de germinação da semente, tanto na presença quanto na ausência de tegumento, e que vários fatores, bióticos e abióticos, influenciam no processo germinativo das sementes, constituindo-se em uma fase crítica, sendo necessário um conjunto de condições favoráveis para que o mesmo possa ocorrer de forma satisfatória (BEWLEY; BLACK, 1994).

Em relação à evolução do processo germinativo do porta-enxerto citrumelo Swingle (Figura 5B), foi possível observar que, aos 60 dias, ocorreu a maior quantidade de sementes germinadas, sem tegumento $(19,17 \%)$ e com tegumento $(78,33 \%)$. 
TABELA 1 - Médias de diâmetro transversal (DT), diâmetro longitudinal (DL), massa do fruto, espessura da "casca" (EC), número de sementes viáveis (NSV) e inviáveis (NSI) dos porta-enxertos Flying Dragon e citrumelo Swingle.

\begin{tabular}{lcccccc}
\hline Porta-enxertos & DT(mm) & DL(mm) & Massa(g) & EC(mm) & NSV & NSI \\
\hline Flying Dragon & $43,6 \mathrm{~b}$ & $42,0 \mathrm{~b}$ & $44,8 \mathrm{~b}$ & $2,8 \mathrm{~b}$ & $26,4 \mathrm{~b}$ & $7,4 \mathrm{a}$ \\
Citrumelo Swingle & $65,0 \mathrm{a}$ & $65,2 \mathrm{a}$ & $129,6 \mathrm{a}$ & $6,4 \mathrm{a}$ & $35,8 \mathrm{a}$ & $31,6 \mathrm{~b}$ \\
\hline Média & 54,3 & 53,6 & 87,2 & 4,6 & 31,1 & 19,5 \\
CV\% & 2,37 & 4 & 10,05 & 10,87 & 7,19 & 11,24 \\
\hline
\end{tabular}

Médias seguidas por letras diferentes, nas colunas, diferem entre si, a 5\% de significância, pela análise de variância.
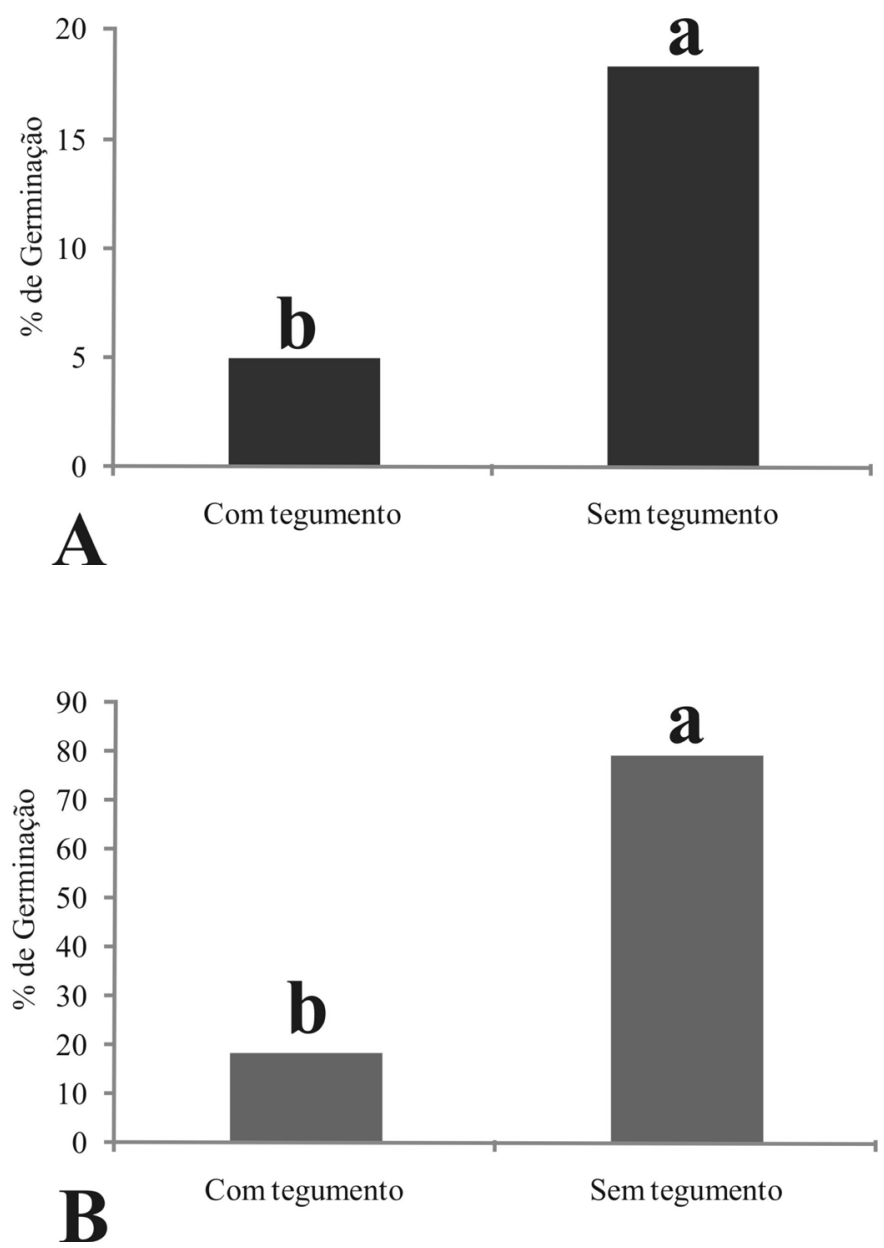

FIGURA 1 - Porcentagem de germinação de sementes do porta-enxerto, com e sem tegumento. A) Flying Dragon; B) Citrumelo Swingle. 


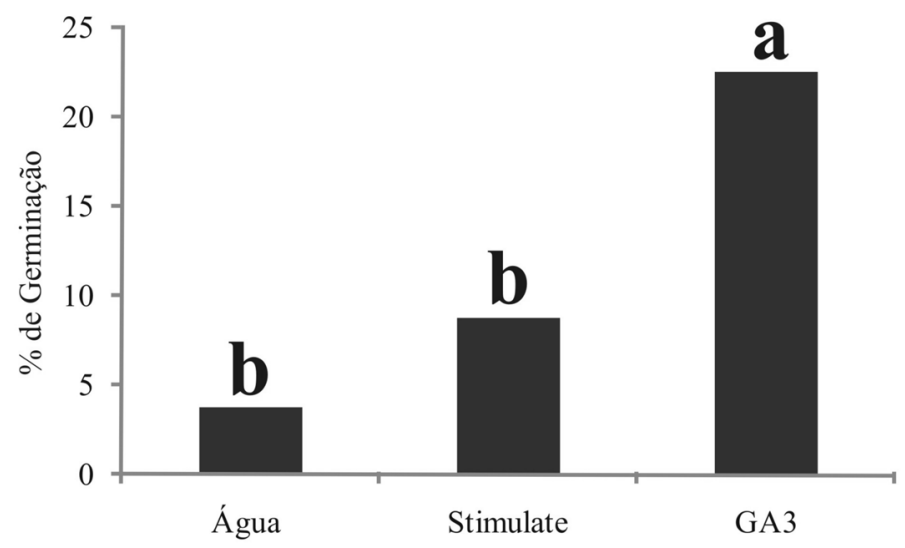

FIGURA 2 - Porcentagem de germinação de sementes do porta-enxerto Flying Dragon submetidas ao tratamento de imersão.

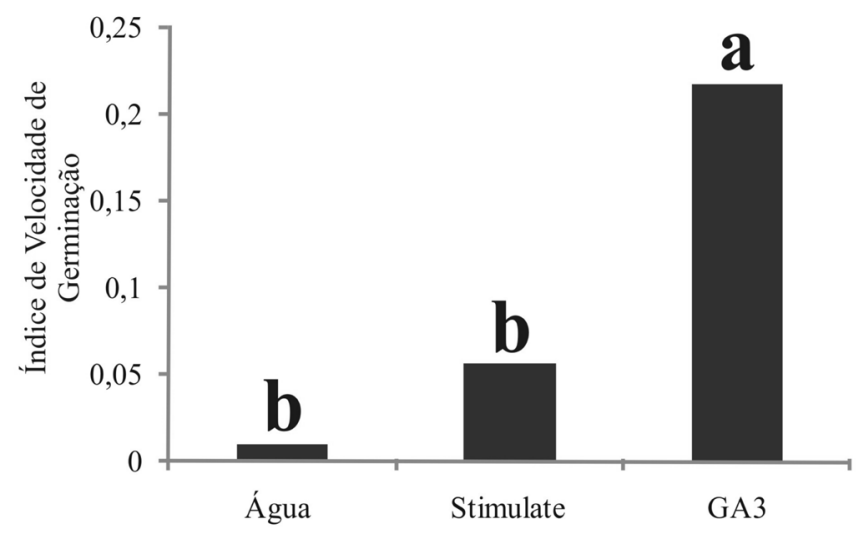

FIGURA 3 - Índice de velocidade de germinação de sementes do porta-enxerto Flying Dragon submetidas ao tratamento de imersão.

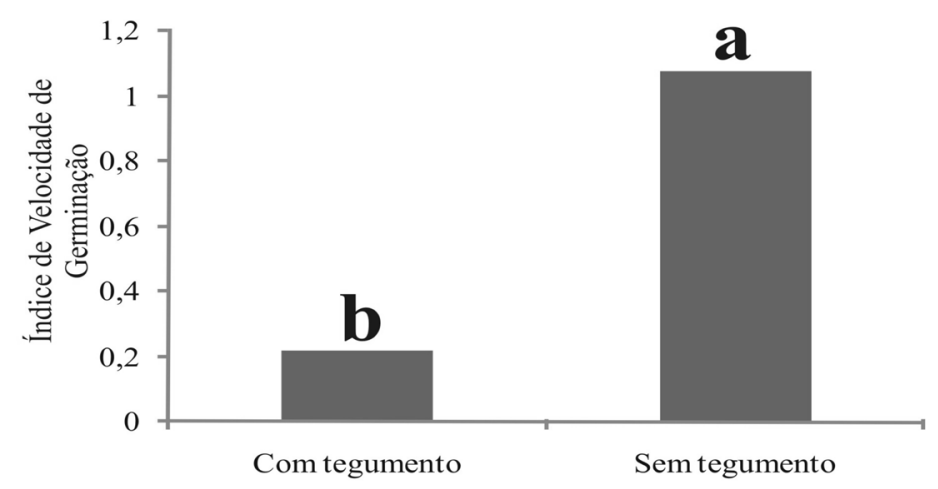

FIGURA 4 - Índice de velocidade de germinação de sementes do porta-enxerto Citrumelo Swingle com e sem tegumento. 


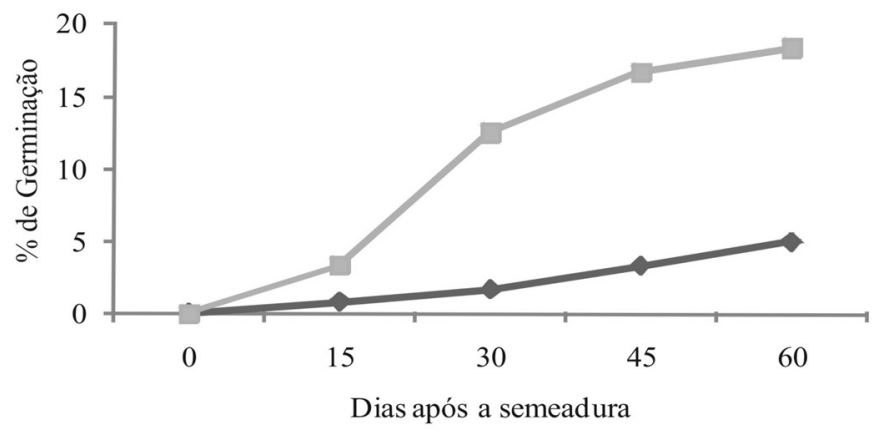

A $\sim$ Com tegumento $=-$ Sem tegumento

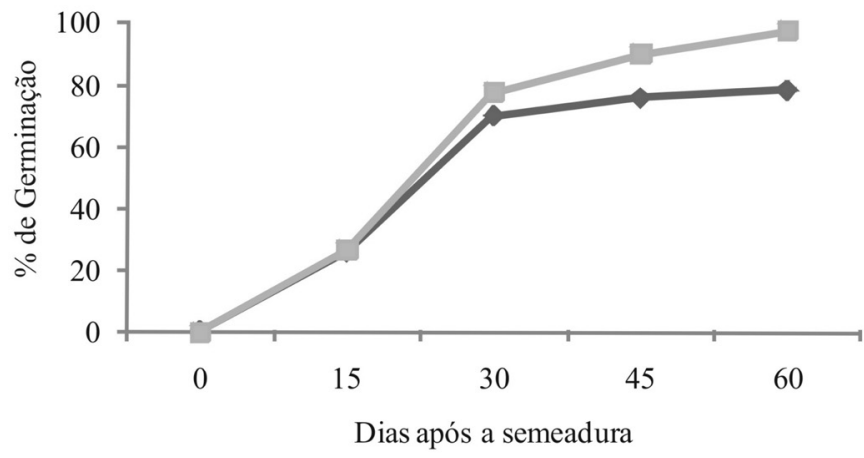

B $\sim$ Com tegumento $=$ Sem tegumento

FIGURA 5 - Evolução do processo germinativo de sementes do porta-enxerto, com e sem tegumento, durante 60 dias. A) Flying Dragon; B) citrumelo Swingle.

\section{CONCLUSÕES}

1-O número de sementes viáveis por fruto do porta-enxerto Flying Dragon é superior ao do portaenxerto citrumelo Swingle, embora este apresente maior número de sementes por fruto.

2-A retirada do tegumento e a utilização do $\mathrm{GA}_{3}$ nas sementes do porta-enxerto Flying Dragon aumentam a porcentagem de germinação e a velocidade da germinação.

3-A retirada do tegumento das sementes do citrumelo Swingle aumenta em $60 \%$ a porcentagem de germinação, enquanto para as sementes do Flying Dragon esse aumento é de apenas 13\%.

\section{REFERÊNCIAS}

AGRIANUAL: anuário da agricultura brasileira. São Paulo: Instituto FNP, 2008. 552p.

BERNARDES, T. G.; NAVES, R. V.; REZENDE, C. F. A.; BORGES J. D.; CHAVES, L. J. Propagação sexuada do pequizeiro (Caryocar brasiliense Camb.) estimulada por ácido giberélico. Pesquisa Agropecuária Tropical, Goiânia, v.38, n.2, p.71-77, 2008.

BEWLEY, J. D.; BLACK, M. Seeds: physiology of development and germination. New York: Plenum Press, 1994. 445p. 
CASTRO, P. R. C.; PACHECO, A. C.; MEDINA, C. L. Efeitos de Stimulate e de micro-citros no desenvolvimento vegetativo e na produtividade da laranjeira 'Pera' (Citrus sinensis L. Osbeck). Scientia Agricola, Piracicaba, v.55, n.2, p.338-341, 1998.

CHILEMBWE, E. H. C.; CAStle, W. S.; CANTLIFFE, D. J. Grading, hydrating and osmotically priming seed of four citrus rootstocks to increase germination rate and seedling uniformity. Journal of the American Society for Horticultural Science, Alexandria, v.117, n.3, p.368-372, 1992.

FERREIRA, D. F. Análises estatísticas por meio do SISVAR para Windows versão 4.0. In.. REUNIÃO ANUAL DA REGIÃO BRASILEIRA DA SOCIEDADE INTERNACIONAL DE BIOMETRIA, 45., 2000, São Carlos. Anais... São Carlos: SIB, 2000. p.255-258.

FORTES, A. M. T. Efeito de reguladores vegetais na propagação de Poncirus Trifoliata (L.) Raf. var. monstrosa, Flying Dragon. 2002. 98 f. Tese (Doutorado em Ciências Biológicas - Fisiologia Vegetal) - Instituto de Biociências, Universidade Estadual Paulista, Botucatu, 2002.

FUNDECITRUS. Disponível em: $<$ http://www.fundecitrus.com.br>. Acesso em: 5 abril 2008.

HORE, J.K.; SEN, S.K. Viability of papaya (Carica papaya L.) seeds under different pre-storage treatments. Environment and Ecology, Lisse,v.11, n.2, p.273-75, 1993.

KELLY, R. J. Abscisic acid and gibberellic acid regulation of seed germination and dormancy. Biologist, Charteston, v.51, n.3, p.91-99, 1969.

LEVITT, J. Introduction to plant physiology. $2^{\text {nd }}$ ed. Saint Louis: The C.V. Mosby, 1974. 447p.

MAGUIRE, J.B. Speed of germination-aid in selection and evaluation for seedling emergence vigor. Crop Science, Madison, v.2, n.2, p.176-177, 1962.

MATTOS JUNIOR, D. de; NEGRI, J. D. de; FI-
GUEIREDO, J. O. de; POMPEU JUNIOR, J. CITROS: principais informações e recomendações de cultivo. Campinas: IAC, 2005.

METIVIER, J. R. Citocininas e giberelinas. In: FERRI, M. G. Fisiologia vegetal. 2.ed. São Paulo: EDUSP, 1986. v.2, cap.4-5, p.93-162.

OLIVEIRA, R. P.; SCIVITTARO, W. B. Formação do porta-enxerto Trifoliata: época de semeadura e tegumento na emergência de plântulas. Revista Ciência Rural, Santa Maria, v.37, n.1, p.281-283, 2007.

ONO, E. O.; RODRIGUES, J. D.; SANTOS, S. O. Efeito de fitorreguladores sobre o desenvolvimento de feijoeiro (Phaseolus vulgaris L.) cv Carioca. Revista Biociências, Taubaté, v.5, n.1, p.7-13, 1999.

PAWSHE, Y. H.; PATIL, B. N.; PATIL, L. P. Effect of pregermination seed treatment on the germination and vigour of seedlings in custard apple (Annona squamosa L.). Annals of Plant Physiology, Akola, v.11, n.2, p.150-154, 1997.

POPINIGIS, F. Fisiologia da semente. Brasília: AGIPLAN/BID, 1977. 288p.

SOARES FILHO, W. dos S. VARIABILIDADE GENÉTICA E MELHORAMENTO DOS CITROS. In: QUEIRÓZ, M. A. de; GOEDERT, C. O.; RAMOS, S. R. R. (Ed.). Recursos genéticos e melhoramento de plantas para o nordeste brasileiro. Petrolina: Embrapa Semiárido/Brasília-DF: Embrapa Recursos Genéticos e Biotecnologia, 1999. Disponível em $<$ http://www.cpatsa.embrapa.br>.

SOUSA, H. U.; RAMOS, J. D.; PASQUAL, M.; FERREIRA, E. A. Efeito do ácido giberélico sobre a germinação de sementes de porta-enxertos cítricos. Revista Brasileira de Fruticultura, Jaboticabal, v.24, n.2, 2002.

STENZEL, N. M. C.; MURATA, I. M.; NEVES, C. S. V. J. Superação de dormência em sementes de atemoia e fruta-do-conde. Revista Brasileira de Fruticultura, Jaboticabal, v.25, n.2, 2003. 
TAIZ, L.; ZEIGER, E. Fisiologia vegetal. Porto Alegre: Artmed, 2004. 135p.

YNOUE, C. K.; ONO, E. O.; MARCHI, L. O. S. Efeito do $\mathrm{GA}_{3}$ na germinação de sementes de kiwi (Actinidia chinensis Planch.). Scientia Agricola, Piracicaba, v.56, n.1, p.9-12, 1999.
ZUCARELI, V.; BONJOVANI, M. R.; CAVARIANI, C.; NAKAGAWA, J. Tolerância à dessecação e influência do tegumento na germinação de sementes de Citrumelo 'Swingle' (Citrus paradisi MACF X Poncirus trifoliata (L) RAF.). Revista Brasileira de Fruticultura, Jaboticabal, v.31, n.1, p.291-295, 2009. 